\section{No 'nanofossils' in}

\section{martian meteorite}

Elongated, segmented forms found on fracture surfaces within the martian meteorite ALH84001 have been proposed to be martian 'nanofossils', even though they appear too small to be fossilized bacteria ${ }^{2-4}$. We have examined similar forms and find that the majority are (non-biological) lamellar growth steps on pyroxene and carbonate crystals. Their segmented surface microstructures are laboratory artefacts resulting from the deposition of conductive heavymetal coatings.

Using transmission electron microscope (TEM) imaging, the definitive method for identifying nanofossils ${ }^{5}$, we have previously observed magnetite whiskers but no nanofossils on or near the surfaces of the carbonates $^{6}$. We suggested that some of the purported nanofossils ${ }^{1}$ might be similar hightemperature, vapour-deposited magnetite whiskers, but the dissimilarity between specimen preparation and electron-beam analysis techniques used in the two studies makes direct comparisons difficult.

We have now examined fracture surfaces from carbonate-rich regions using the techniques described by McKay et al. ${ }^{1}$. Chips of ALH84001 with exposed carbonate and pyroxene crystals were mounted, coated
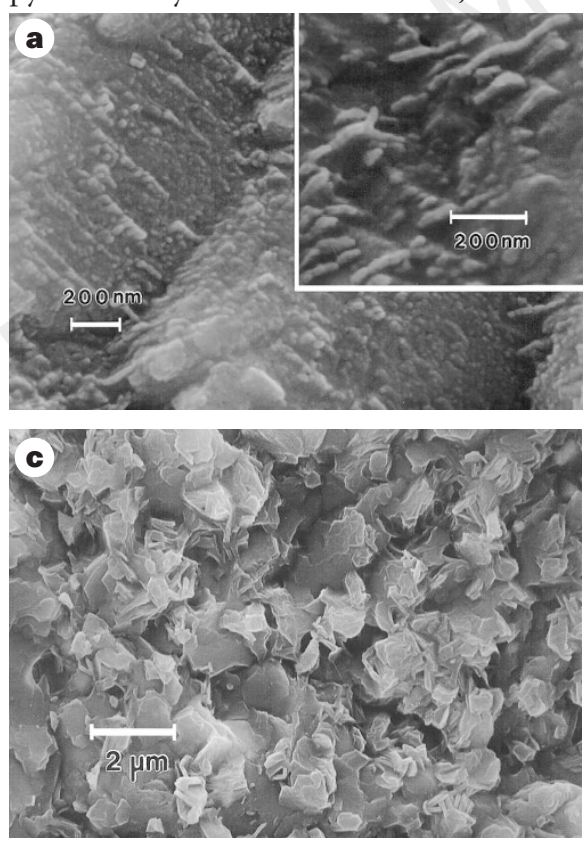

Figure 1 'Elongated forms' in the meteorite ALH84001. a, Secondary electron image of pyroxene surface. Parallel elongated forms (from upper left to lower right) are emergent lamellae related to substrate cleavage direction. Inset, pyroxene surface oriented such that elongated forms resemble nanofossils. Both surfaces have a 10-nm-thick coating of gold, measured by TEM imaging of ultramicrotomed cross-sections. b, Secondary electron images of highly fractured pyroxene surface. Inset, high-magnification image of lamellae. Coating: $20 \mathrm{~nm}$ Au, resulting in more pronounced segmentation. c, Secondary electron image of carbonate crystals (coated with $9 \mathrm{~nm}$ of Au/Pd). The average grain size is $<1 \mu \mathrm{m}$ as suggested by previous work ${ }^{9}$. d, Secondary electron image of carbonate surface within fracture zone. Inset, high-magnification image of elongated forms on carbonate, some of which may be magnetite whiskers ${ }^{6}$. Coating: $10 \mathrm{~nm}$ Au. of the elongated forms in ALH84001 (Fig. 1a, b) are largely an artefact of the conductive metal coating. Similar coating artefacts have previously been misidentified as (terrestrial) nanofossils ${ }^{7}$. Au and $\mathrm{Au} / \mathrm{Pd}$ coatings produce segmentation on elongated forms, although $\mathrm{Au} / \mathrm{Pd}$ imparts a finer-scale segmentation (as seen in the images in refs 1 and 8). In addition, the segmentation becomes more pronounced as the coating thickness is increased ${ }^{7}$ (compare Fig. 1a and b). As noted by McKay et al. ${ }^{1}$, specimen charging is a problem with some chips of ALH84001, because the minerals are insulators and because some chips are shattered (shock-fractured) on a submicrometre scale. A conductive coating is desirable for secondary electron imaging, and the optimum coating (composition and thickness) is a trade-off between charging effects, surface artefacts (enhanced segmentation) and required image resolution.

The complexity of the pyroxene and carbonate fracture surfaces in ALH84001 probably reflects the superposition of severe shock and/or thermal events on indigenous surface microstructures of the minerals ${ }^{9,10}$. Many of the lamellae relate to internal cleavage planes within the pyroxene and carbonate substrates, and their orientations may reflect localized shock deformation, partial melting, or even the onset of secondary alteration (for example, clay formation ${ }^{11}$ ). Where lamellae are exposed on fracture surfaces, their enhanced secondary electron yield (a characteristic of lamellar surfaces ${ }^{12,13}$ ) and segmented surface structures (an artefact of the metal coating) combine to produce the nanofossil-like appearance.

Although some of the elongated forms of ALH84001 could conceivably be martian nanofossils, the majority appear to be either emergent substrate lamellae or magnetite whiskers ${ }^{6}$. Some lamellae may exhibit indigenous segmentation ${ }^{14}$, but conductive metal coatings both produce and accentuate segmentation which is particularly prominent in high-resolution FE-SEM images. TEM imaging is therefore more appropriate for distinguishing coated lamellae from 'nanofossils', as it is possible to observe internal microstructures characteristic of nonbiogenic $^{6}$ and biogenic ${ }^{5}$ 'elongated forms'.

\section{J. P. Bradley}

MVA Inc., 5500/200 Oakbrook Parkway,

Norcross, Georgia 30093, USA

and School of Materials Science and Engineering,

Georgia Institute of Technology,

Atlanta, Georgia 30332-0245, USA

\section{R. P. Harvey}

Department of Geological Sciences,

Case Western Reserve University, Cleveland,

Ohio 44106-7216, USA

\section{H. Y. McSween Jr}

Department of Geological Sciences,

University of Tennessee, Knoxville,

Tennessee 37996-1410, USA 
McKay et al. reply - We are aware that some mineral surfaces of ALH84001 display very narrow elongated forms, often subparallel, in the nanometre size range (Fig. $2 \mathrm{a}, \mathrm{b}$ here and Fig. 1a, b and d of Bradley et al.). They are very common on pyroxene surfaces, but also occur on carbonate surfaces. We have also imaged some of these features, which Bradley et al. propose are simply emergent edges of pyroxene lamellae, with a field emission scanning electron microscope (FE-SEM). We have previously reported the presence of small amounts of clay minerals in ALH84001 from TEM images and electron diffraction data ${ }^{11}$. We propose that the features in Fig. 2a, b here and Fig. 1b of Bradley et al. may be weathering features caused by incipient formation of clay minerals. In places, these figures have a 'platy' appearance characteristic of some clay minerals especially in the uncoated ALH84001 sample (Fig. 2a). Regardless of their exact origin, it is unlikely that these features are biogenic.

By contrast, the features that we imaged previously (Fig 6b in ref. 1) are not subparallel. They display intersecting alignment, have significant curvature and are more isolated. In addition, features tentatively interpreted as martian nanofossils are larger than the lamellae or elongated magnetite reported by Bradley et al. ${ }^{6}$. Curved and $\mathrm{S}$-shaped features from the surfaces of carbonate globules are up to $0.75 \mu \mathrm{m}$ in length (Fig. 2c), an order of magnitude larger than the 'lamellae' or the elongated magnetite observed by Bradley et al. ${ }^{6}$. Additionally, some of the features we proposed as possible martian microfossils are ovoid rather than elongated (Fig. 6a in ref. 1).

It is well known that conductive coatings can alter appearance, cover fine details and produce artefacts. We ran a series of controls for coating artefacts (ref. 50 in ref. 1). Carbon coating of ALH84001 samples obscures fine honeycomb-like surface texture and many of the larger features become rounded or softened (Fig. 2d, e). However, the dimensions of the larger features are not appreciably affected (Fig. 2d, e).

Previous studies on latex spheres ${ }^{15}$ show that coatings of $\mathrm{Au}$ produce larger artefact grains than $\mathrm{Au} / \mathrm{Pd}$; grain size of $\mathrm{Au}$ is $2-3$ times larger than $\mathrm{Au} / \mathrm{Pd}^{16}$. Bradley et al. used $\mathrm{Au}$ in producing their high-magnification images, so the purported artefact segmentation would naturally be more prominent than if $\mathrm{Au} / \mathrm{Pd}$ were used. We used $\mathrm{Au} / \mathrm{Pd}$, carbon, or completely uncoated samples in our studies, never gold alone, and have also made control coatings on lunar glass surfaces using 30 and 60 seconds ( $\sim 10$ and $20 \mathrm{~nm}$ thick, respectively) of $\mathrm{Au} / \mathrm{Pd}$ from our coater. The glass is not exactly analogous to the minerals in ALH84001 (except perhaps for the feldspathic glass), and artefacts are substrate-
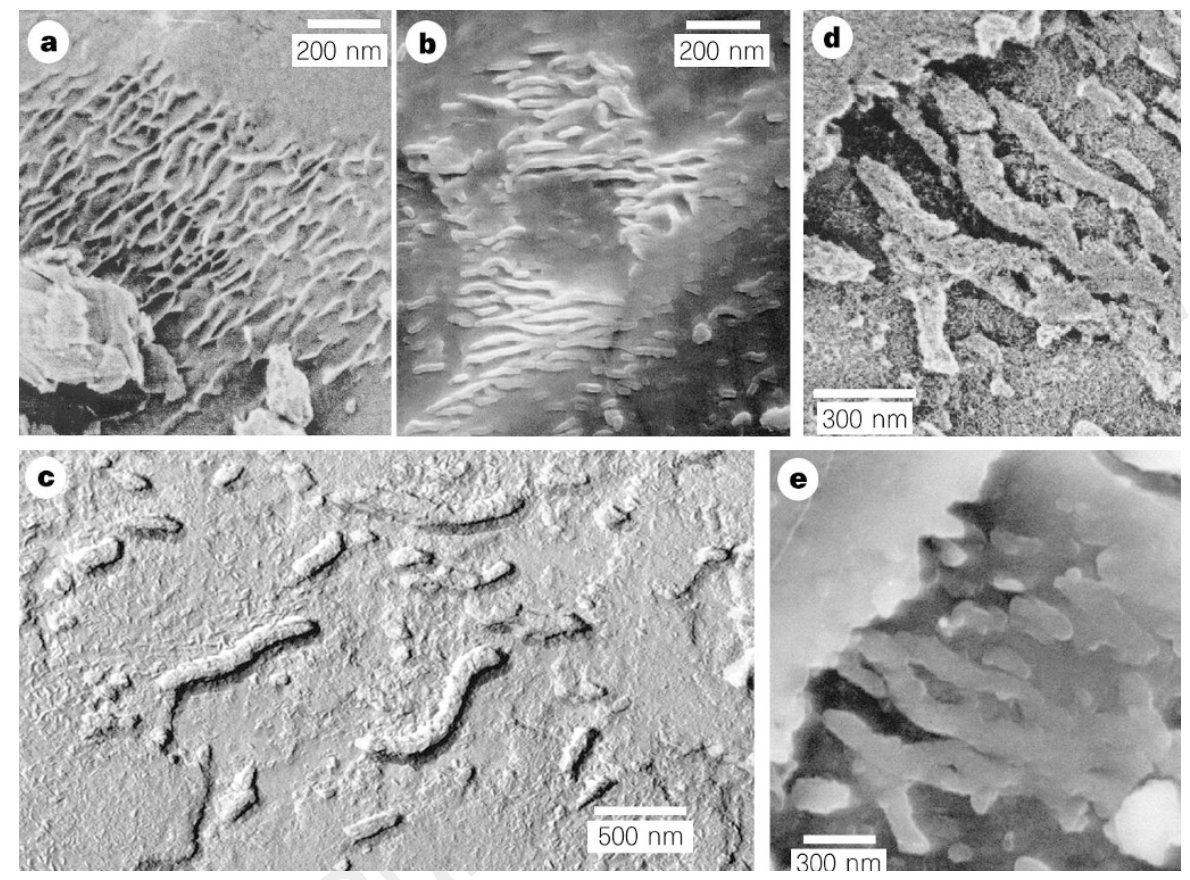

Figure 2 FE-SEM images of ALH84001 samples. a, Fine-scale platy texture on a carbonate surface in ALH84001. The sample was imaged at $1 \mathrm{kV}$ without any conductive coating. $\mathbf{b}$, The same surface after coating with a thin $(\sim 10 \mathrm{~nm})$ carbon layer. c, TEM image of a shadowed replica of part of a carbonate surface from ALH84001. The replica was made from an uncoated surface so textures in the image represent true textures of the surface. These elongate features are much larger than either the platy structures in (a) or the 'lamellae' and whisker magnetite described by Bradley et al. ${ }^{6} . \mathbf{d}$, Texture on the surface of an uncoated carbonate in ALH84001 imaged at $1 \mathrm{kV}$. Note the fine-grained wispy texture which we interpret as an extremely thin clay mineral alteration of the carbonate. e, The same sample now coated with $\sim 10 \mathrm{~nm}$ of carbon and imaged at $10 \mathrm{kV}$. Note that all of the large strand features are visible and relatively unchanged although space between them has been partly filled. The fine wispy surface now looks smooth.

dependent, but its smooth surface is ideal for detecting coating artefacts. At $30 \mathrm{~s}$ there are no artefacts and at $60 \mathrm{~s}$ only a fine uniform cracking or crazing texture is apparent. For our original ALH84001 studies, we generally used $30 \mathrm{~s}$ or less (and never more than $60 \mathrm{~s}$ ) for sample coating. Although some of our images may have a fine crazing resulting from the coating, we have not observed major decoration in any of our control samples. ALH84001 substrates may accentuate and amplify coating artefacts more than our controls, but we have no evidence for such anomalous behaviour.

Bradley et al. suggest that the purported martian nanofossils are too small for fossilized bacteria. In fact, the lower size limit of fossilized bacteria has not been determined. In mammalian blood, living bacteria as small as $70 \mathrm{~nm}$ in diameter have been found which contain identifiable DNA and can reproduce ${ }^{17,18}$. Also, soil bacteria as small as $80 \mathrm{~nm}$ have been found ${ }^{19}$.

Bradley et al. suggested that the purported elongated microfossils may be hightemperature, vapour-formed magnetite whiskers, but other studies have shown that the carbonate globules and their included magnetites could not have formed at temperatures above $100-300{ }^{\circ} \mathrm{C}^{20-22}$ whereas elongate magnetite grains can be produced by bacteria at low temperatures ${ }^{23,24}$. They also assert that TEM imaging is more appropriate for identifying nanofossils, as it is possible to distinguish internal microstructures. SEM and TEM imaging are complementary and the use of both methods on the same samples would provide the best evidence for biogenic activity, particularly when internal structure is destroyed or replaced by mineralization ${ }^{25,26}$.

David S. McKay, Everett Gibson Jr

NASA Johnson Space Center,

Houston, Texas 77058, USA

e-mail: david.s.mckay1@jsc.nasa.gov

\section{Kathie Thomas-Keprta}

Lockheed Martin, 2400 NASA Road 1, C-23,

Houston, Texas 77058, USA

H. Vali

McGill University, 3450 University Street,

Montreal, Quebec H3A 2A7, Canada

1. McKay, D. S. et al. Science 273, 924-930 (1996).

2. Maniloff, J. Science 276, 1776 (1997).

3. Nealson, K. H. Science 276, 1776 (1997).

4. Psenner, R. \& Loferer, M. Science 276, 1776-1777 (1997).

5. Bazylinski, D. A. ASM News 61, 337-340 (1975).

6. Bradley, J. P., Harvey, R. \& McSween, H. Y. Jr Geochim. Cosmochim. Acta 60, 475-481 (1996).

7. Folk, R.L. et al. J. Sedim. Res. 67, 583-587 (1997).

8. Kerr, R. A. Science 276, 30-31 (1997).

9. Harvey, R. P. \& McSween, H. Y. Jr Nature 382, 49-51 (1996).

10. Scott, E. R. D., Yamaguchi, A. \& Krot, A. N. Nature 387 377-379 (1997).

11. Thomas-Keprta, K. L. et al. Lunar Planet. Sci. 28, 1433-1434 (1997)

12. Goldstein, J. I. \& Yakowitz, H. (eds) Practical Scanning Electron Microscopy (Plenum, New York, 1975). 
13. Brooks, C. R. \& Bogni, F. Mater. Character. 38, 103-117 (1997) 14. Steele, A. et al. Lunar Planet. Sci. 28, 1369-1370 (1997).

15. Morrison, D. A. \& Clanton, U. S. Proc. Lunar Planet. Sci. Conf. 10, 1649-1663 (1979)

16. Newbury, D. E., Joy, D. C., Echlin, P., Fiori, C. E. \& Goldstein, J. I. in Advanced Scanning Electron Microscopy and X-Ray Microanalysis (Plenum, New York, 1986).

17. Kajander, E. O., Kuronen, I., Åkerman, K., Pelttari, A. \& Ciftçioglu, N. in Proc. Soc. Photo-Opt. Instrum. Eng. Vol. 3111 (ed. Hoover, R. B.) 420-428 (Int. Soc. Opt. Eng., Bellingham, WA 1997).

18. Ciftçioglu, N., Pelttari, A. \& Kajander, E. O. in Proc. Soc. PhotoOpt. Instrum. Eng. Vol. 3111 (ed. Hoover, R. B.) 429-435 (Int. Soc. Opt. Eng., Bellingham, WA 1997).

19. Kieft T. L. in Nonculturable Microorganisms in the Environment (eds Colwell, R. R. \& Grimes, D. J.) (Chapman and Hall, New York, in the press).

20. Romanek, C. S. et al. Nature 372, 655-657 (1994).

21. Valley, J. W. et al. Science 275, 1633-1638 (1997).

22. Gleason, J. D., Kring, D. A., Hill, D. H. \& Boynton, W. V. Geochim. Cosmochim. Acta 61, 3503-3512 (1997).

23. Hanzlik M., Winklhofer M. \& Petersen N. Earth Planet. Sci. Lett. 145, 125-134 (1996).

24. von Dobeneck T., Petersen N. \& Vali H. Geowiss. Uns. Zeit 1, 27-35 (1987).

25. Westall, E. in Astronomical and Biochemical Origins and the Search for Life in the Universe (eds Cosmovici, C.B., Bowyer, S. \& Werthimer, D.) 491-504 (Compositori Editrice, Bologna, 1997).

26. Westall F. Darmstädter Beiträge zur Naturges. 4, 29-43 (1994).

\section{Travelling waves in vole population dynamics}

Spatial self-organization patterns in population dynamics have been anticipated ${ }^{1-3}$, but demonstrating their existence requires sampling over long periods of time at a range of sites. Voles cause severe economic damage and are therefore extensively
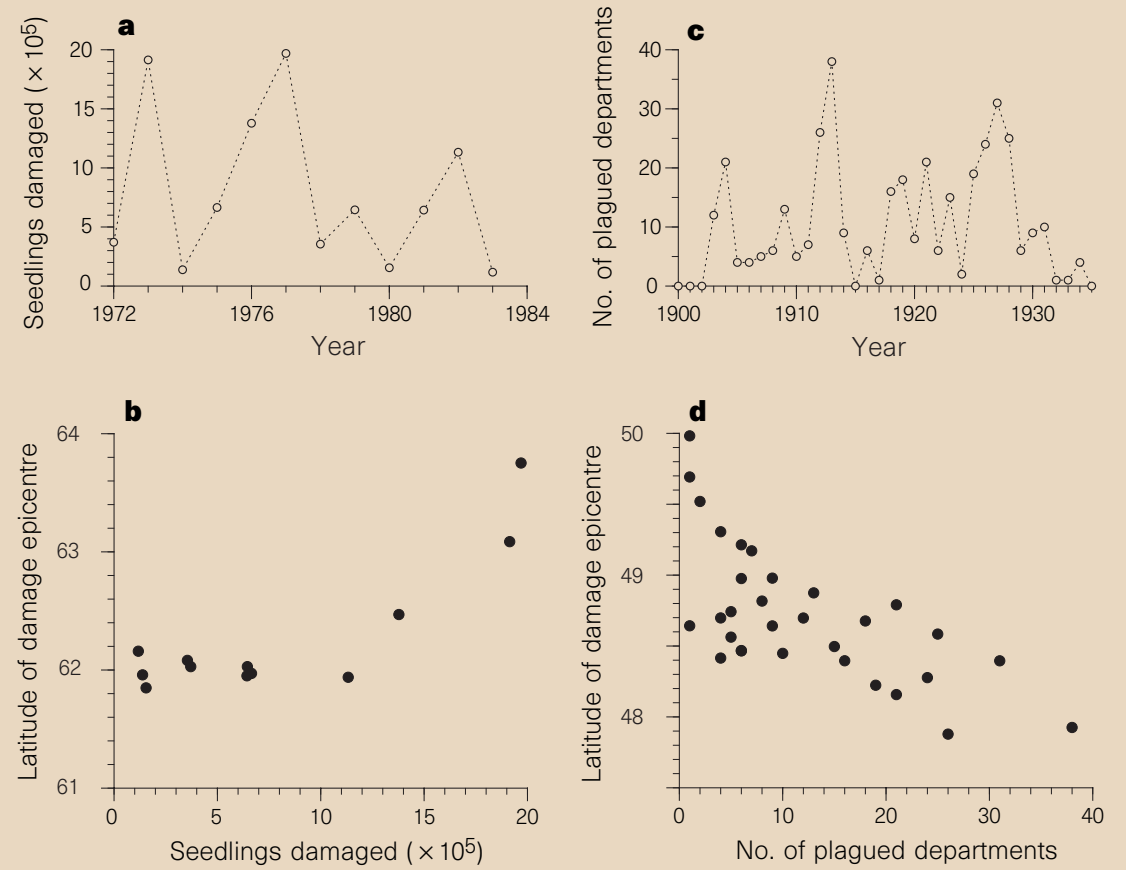

Figure 1 Extent and severity of vole damage. a, The number of seedlings destroyed by voles on study plots in young forest plantations in Finland ${ }^{5,6} . \mathbf{b}$, The dynamics are characterized by movement of the annual damage epicentre from south to north as total damage increases. c, Geographical extent of French ${ }^{4}$ vole plagues; and $\mathbf{d}$, annual epicentre of plagues plotted against the number of plagued departments. like those seen in the Scandinavian voles ${ }^{7}$. Again there was a correlation between the latitude of the annual location of the centre of mass and the geographical extent of the damage $(r=-0.67, P<0.001$; for the longitude $r=0.06)$. Accordingly, the French vole plagues spread from north to south, whereas in Finland they spread from south to north.

A variable is said to be spatially autocorrelated when it is possible to predict the values of this variable in one site from the known values at nearby sampling sites ${ }^{9}$. We performed autocorrelation analyses for irregularly spaced interval (Finland) or nominal scales (France) ${ }^{10}$.

For the Finnish data, we computed annual autocorrelation coefficients ${ }^{9-11}$ for the distance class of $200 \mathrm{~km}$ assuming binary links. We detected significant positive spatial autocorrelation in six of the twelve years. For the French data we computed annual spatial autocorrelations using binary weights and assuming a link between sites that were less than $120 \mathrm{~km}$ apart. We found a significant spatial autocorrelation present in the data in 14 of the 33 years. Both results indicate that spatial structure exists in these populations.

By identifying spatial autocorrelation in vole populations and an annually moving epicentre of vole plagues as a function of damage extent, we conclude that travelling waves, or pulses, in the dynamics of vole populations exist, a phenomenon predicted $^{1-3}$ by theoretical population ecology.

\section{Esa Ranta}

Department of Ecology and Systematics,

University of Helsinki,

PO Box 17,

FIN-00014 Helsinki,

Finland

e-mail:esa.ranta@helsinki.fi

\section{Veijo Kaitala}

Department of Biological and Environmental

Science,

University of Jyväskylä,

Box 35,

FIN-40351 Jyväskylä,

Finland

1. Hassell, M. P., Comins, H. N. \& May, R. M. Nature 353, 255-258 (1991).

2. Rohani, P. \& Miramontes, O. Proc. R. Soc. Lond. B 260, 335-342 (1995).

3. Bascompte, J. \& Sole, R. Trends Ecol. Evol. 10, 361-366 (1995).

4. Elton, C. Voles, Mice and Lemmings. Problems in Population Dynamics (Clarendon, Oxford, 1942).

5. Teivainen, T. Folia Forestalia 387, 1-23 (1979).

6. Teivainen, T. Metsäntutkimuslaitoksen Tiedonantoja 145, 1-12 (1984).

7. Hansson, L. \& Henttonen, H. Oecologia 67, 394-402 (1985).

8. Ranta, E., Kaitala, V., Lindström J. \& Lindén, H. Proc. R. Soc. Lond. B 262, 113-118 (1995).

9. Sokal, R. R. \& Oden, F. M. L. S. Biol. J. Linn. Soc. 10, 199-228 (1978)

10. Legendre, P. \& Fortin M.-J. Vegetatio 80, 107-138 (1989). 11. Moran, P. A. P. Biometrika 37, 17-23 (1950). 